\title{
Trolleys and Double Effect in Experimental Ethics
}

\author{
Ezio Di Nucci (Universität Duisburg-Essen, ezio.dinucci@uni-due.de)
}

\begin{abstract}
I analyse the relationship between the Doctrine of Double Effect and the Trolley Problem: the former offers a solution for the latter only on the premise that killing the one in Bystander at the Switch is permissible. Here I offer both empirical and theoretical arguments against the permissibility of killing the one: firstly, I present data from my own empirical studies according to which the intuition that killing the one is permissible is neither widespread nor stable; secondly, I defend a normative principle according to which killing the one in Bystander at the Switch is not permissible. In conclusion, there just is no trolley problem.
\end{abstract}

\section{Trolleys and Double Effect}

In one of analytic philosophy's infamous thought-experiments, a runaway trolley is about to kill five workmen who cannot move off the tracks quickly enough; their only chance is for a bystander to flip a switch to divert the trolley onto a side-track, where one workman would be killed. In a parallel scenario, the bystander's only chance to save the five is to push a fat man off a bridge onto the tracks: that will stop the trolley but the fat man will die. Why is it permissible for the bystander to divert the trolley onto the one workman by pressing the switch while it is not permissible for the bystander to stop the trolley by pushing the fat man off the bridge? This is the so-called Trolley Problem, resulting from Judith Jarvis Thomson's (1976 \& 1985) adaptation of an example from Philippa Foot (1967). If it is permissible to intervene in the so-called Bystander at the Switch scenario while it is not permissible to intervene in the so-called Fat Man scenario, then the Trolley Problem arises and we must explain the moral difference between these two cases. And if the results of Marc Hauser's Moral Sense Test are to be believed, then according to public opinion it is indeed permissible to intervene in the former case (around $90 \%$ of respondents to the Moral Sense Test thought as much - Hauser 2006: 139) while it is not permissible to intervene in the latter case (only around $10 \%$ of respondents thought it permissible to intervene).

The Doctrine of Double Effect is a normative principle according to which in pursuing the good it is sometimes morally permissible to bring about some evil as a side-effect or merely foreseen consequence: the same evil would not be morally justified as an intended means or end. ${ }^{i}$ The Doctrine of Double Effect, it could be argued, offers a possible answer to the Trolley Problem, because it can be deployed to argue that the difference in moral permissibility results from the one being killed as a means to saving the five in Fat Man; while in Bystander at the Switch the killing of the one is a mere side-effect of saving the five. In this respect, as long as the Trolley Problem remains 'unsolved' it offers dialectical support to the Doctrine of Double Effect. So the connection between the Doctrine of Double Effect and the 
Trolley Problem is dialectically very simple: the Trolley Problem counts as an argument in favour of the Doctrine in so far as it remains an unresolved problem and in so far as the Doctrine offers a possible solution to this unresolved problem.

The relationship between the Doctrine of Double Effect and the Trolley Problem can be then summarized as follows:

(1) The Doctrine of Double Effect offers a solution to the Trolley Problem;

(2) The two scenarios which constitute the Trolley Problem illustrate the distinction between 'means' and 'side-effects' which, according to the Doctrine of Double Effect, is morally relevant;

(3) Widespread moral intuitions about the Trolley Problem suggest that, just as the Doctrine of Double Effect says, the distinction between 'means' and 'side-effects' is indeed morally relevant.

The philosophical debate on the Doctrine of Double Effect faces a continuing stall: on the one hand the Doctrine has - intuitively - much to be said in its favour, but on the other hand it cannot be coherently formulated and applied (as I have argued at length in my book Ethics Without Intention). How are we then to overcome this philosophical stall, which often leads to endorsement of the Doctrine notwithstanding its 'problems of application' (as Thomas Nagel

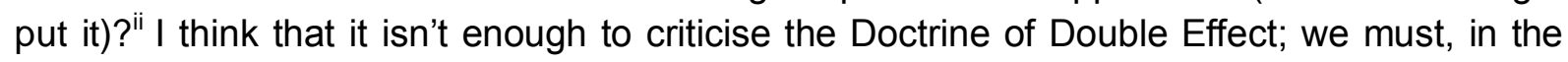
spirit of Philippa Foot, also offer an alternative explanation of the cases, such as the Trolley Problem, which motivate it.iii

To this end here I defend both empirically and theoretically a recent argument for the claim that there is no trolley problem because even in Bystander at the Switch it is not permissible to intervene: on the empirical side of things, I present data showing that the intuition that intervening in Bystander at the Switch is permissible is neither stable nor widespread and that it is subject to some classic order effects. And on the theoretical side I defend the normative claim that intervening is not permissible.

\section{The empirical argument against the permissibility of killing the one}

There are two obvious ways to go about the Trolley Problem: one can either explain the moral difference between the two scenarios, or one can deny that there is such a difference, by either denying that it is permissible to kill the one workman in Bystander at the Switch or by denying that it is not permissible to kill the fat man in the other scenario. Interestingly, Thomson (2008) herself has recently argued that there is no Trolley Problem by denying that it is permissible to intervene in Bystander at the Switch. Thomson's argument moves from a variant in which you also have the chance to divert the trolley onto yourself (you are on a third track and you can't move off it quickly enough). If you would not be willing to divert the trolley onto yourself - sacrificing your own life to save the five - then it would be preposterous to sacrifice someone else: it is just not fair.

Someone who would not sacrifice herself in this new scenario ought not to sacrifice someone else in the original Bystander at the Switch; or so Thomson argues: "Since he wouldn't himself pay the cost of his good deed if he could pay it, there is no way in which he can 
decently regard himself as entitled to make someone else pay it" (2008: 366). Here folk intuitions aren't clear-cut: $43 \%$ would still kill the one; $38 \%$ would commit self-sacrifice; and $19 \%$ would not act, letting the trolley kill the five (Huebner \& Hauser 2011).

If these numbers are to be believed, they can be used against Thomson's argument, since more than $40 \%$ would still kill the one; but also in favour of it, since almost $40 \%$ would commit self-sacrifice; and, perhaps more importantly, the majority (almost $60 \%$ ) would now not kill the one, while in the traditional Bystander at the Switch it was only around $10 \%$. ${ }^{\text {iv }}$

But there is another respect in which the numbers are not decisive: Thomson's argument is about the effect of this new three-way scenario on the traditional two-way Bystander at the Switch. And these numbers are silent on that - what should then be tested is how folk intuitions would respond to the traditional scenario after having been subjected to the new three-way scenario: if the 9 to 1 proportion would even out somewhat, that would speak in favour of Thomson's argument.

Experiments that I conducted suggested just that: participants who were not previously familiar with any of the trolley scenarios were presented first with Thomson's new three-way scenario and then with the traditional Bystander at the Switch. Answers to Bystander at the Switch were radically different from the 9 to 1 proportion identified by Hauser, so much so that the majority $(61,34 \%)$ opted to let the five workmen die.

For details on my studies please see Di Nucci (2013a): here I will just graphically sum up the results and then discuss them.

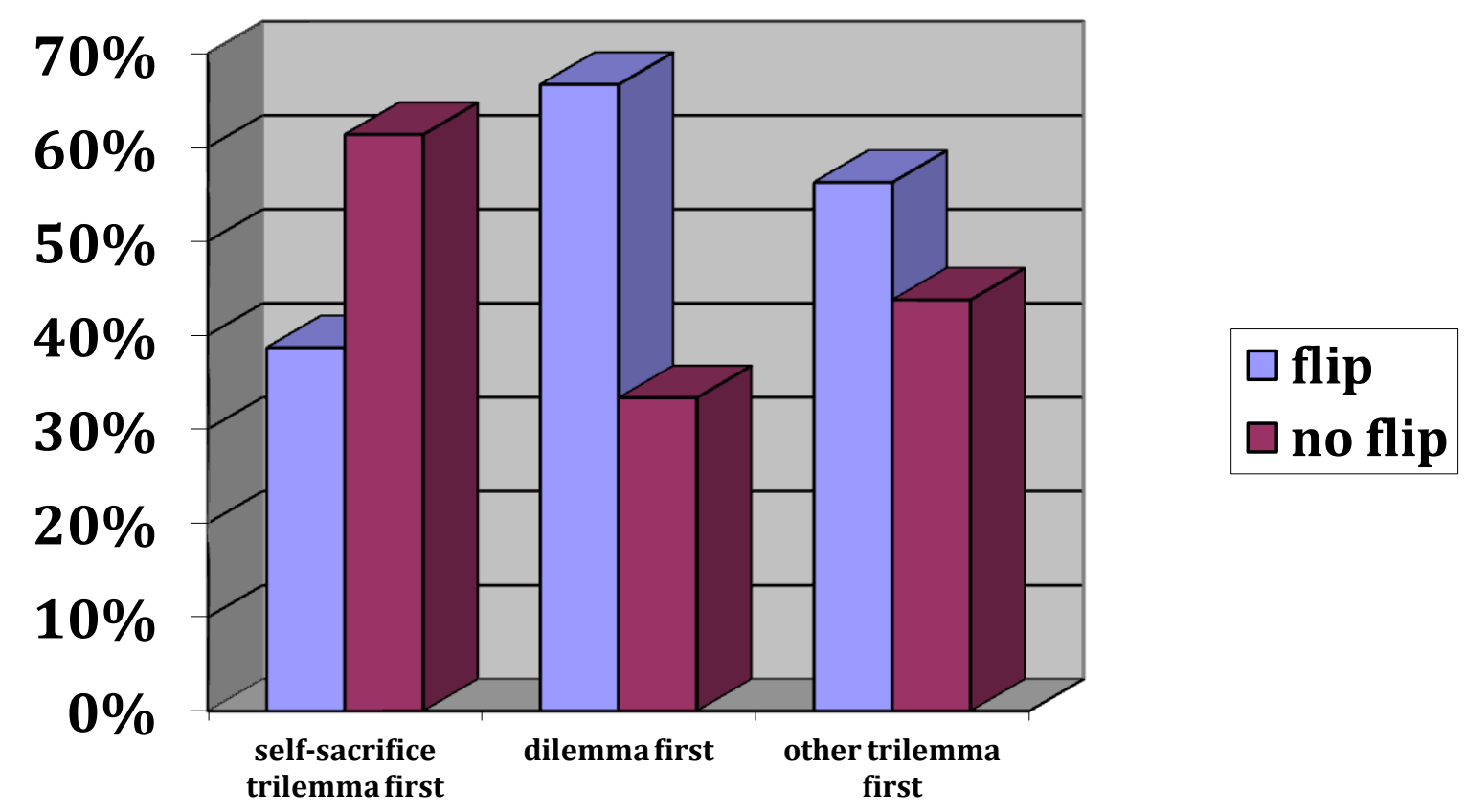

Figure 1: The Trolley Trilemma

So it seems that the apparently overwhelming intuition that intervening in Bystander is permissible disappears when subjects are presented with Bystander only after they have been asked about Thomson's new scenario. Indeed, after having considered a scenario in 
which they could also sacrifice themselves, a majority of subjects appear to think that intervening in Bystander is not permissible. As anticipated above, these results support Thomson's claim that her new scenario has a bearing on the permissibility of intervening in Bystander: we can suppose that subjects who have just been asked about the self-sacrifice scenario may overwhelmingly opt to let the five die in Bystander at the Switch because they now recognise that they may not do to the one what they would not do to themselves.

It may be objected that these results do not support Thomson's new argument; they rather just show that the relevant moral intuitions are very unstable. This is after all the conclusion Swain et al. (2008) drew following their own experimental philosophy studies where the order in which the cases were presented affected results (see also, for other examples of this sort of effect, Petrinovich \& O'Neill 1996; Sinnott-Armstrong 2008; Wiegmann et al. 2010). I think that the dialectic of Thomson's argument is such that our results do support it, because her argument is about the effect of the new case on the old one; but even if you disagree, then our results would show, in line with Swain et al. (2008), that the Bystander intuition is unstable and that it depends on the order of presentation so heavily that it disappears (less than $40 \%$ have it) when Bystander is first introduced after Thomson's new self-sacrifice case.

Even if Hauser's data is reliable, then, the numbers are not decisive one way or another for Thomson's argument, because they can be interpreted both in favour of Thomson's argument and against it, and because the more relevant questions have not been asked when the right questions are asked, then, as our numbers above show, intuitions seem to support Thomson's argument. ${ }^{v}$

\section{The theoretical argument against the permissibility of killing the one}

The empirical challenges against Thomson fail then; but there has also been a theoretical critique of Thomson's new argument. According to Thomson, her new case brings out the principle that "A must not kill $B$ to save five if he can instead kill himself to save the five" (2008: 365). William J. FitzPatrick has recently argued (2009) against this principle by suggesting that the values of equality and fairness that Thomson's argument appeals to can be captured by a weaker principle that does not support Thomson's conclusion. According to FitzPatrick, we need not accept, with Thomson, that "A's respecting $B$ as a moral equal requires that $A$ not sacrifice $B$ (without $B$ 's consent) for end $E$ unless $A$ would be willing to sacrifice himself for $E$ if he could do so instead" (2009: 639). Moral equality may be satisfied by appeal to the weaker principle according to which " $A$ 's respecting $B$ as a moral equal requires that $A$ not sacrifice $B$ for end $E$ unless $A$ recognizes $B$ 's equal right to sacrifice $A$ for E if their positions were reversed" (639). On the former principle, I may not sacrifice the bystander if I would not be willing to sacrifice myself; but on the latter principle I may, as long as I recognise the bystander's right to sacrifice me if our positions were reversed. On this latter understanding, then, fairness would not support Thomson's argument that it is not permissible to intervene in Bystander at the Switch.

It may be argued that employing FitzPatrick's latter principle in the debate on the Trolley Problem is methodologically suspect because it introduces 'rights': what's at stake are exactly the sort of fundamental principles that may be deployed to justify rights, rather than the other way around. But there is a bigger worry with FitzPatrick's alternative principle: the problem is that this is no principle to capture fairness or, as FitzPatrick puts it, "respecting others as moral equals" (2009: 639). His principle amounts to the Law of the Jungle: it just 
says that whoever happens to find herself at the switch may take advantage of this (lucky or otherwise) circumstance and kill the other. It doesn't have anything to do with fairness or equality; it is sheer power and privilege. The point is not whether this perspective is defensible; it is just that, even if it is, this is not the point of view of fairness or 'respecting others as moral equals'. Here the dialectic of the argument is important: FitzPatrick doesn't argue for his alternative principle on the grounds that Thomson's own principle is flawed, but only on the grounds that his own less demanding principle also accounts for fairness and 'respecting others as moral equals'. That is why what is crucial is whether his principle does indeed account for fairness and 'respecting others as moral equals' rather than whether it is, in absolute terms, defensible.

This alternative principle does not support FitzPatrick's argument. What about the principle's intrinsic value, so to speak? In some particular set of circumstances, I may kill you only if I recognise your equal right to kill me if our positions were reversed. What may my recognition of your equal right to kill me amount to? Maybe if you were at the switch and diverted the trolley towards me, my recognition of your equal right to kill me means that I may not, as I die, swear at you; or that, as the trolley approaches, I should quickly try to write a note saying that I don't blame you. But wouldn't that problematically amount to consent? This would be problematic because the question is whether I may divert the trolley onto your track irrespective of your consent. But I think it is both complicated and uncharitable to test the principle's intrinsic value on the Trolley Problem. What about its more general application? The idea that I recognise your right to kill me if our positions were reserved must mean, for example, that if our positions were reserved, and you were threatening to kill me, I should not defend myself or try to stop you, because I recognise your right to kill me, after all. And this isn't just weird, it is also against the spirit of the principle itself: if whoever gets to the switch first may kill the other, then you would expect that we are allowed to take advantage of our privileged positions; but then why should I let you kill me? In short, the principle bears contradicting responses: it asks us on the one hand to recognise the other's right to kill us, and on the other hand it justifies this right with the other's privileged position.

The principle is too Machiavellian to count as a principle of fairness or 'respecting others as moral equals', but it isn't Machiavellian enough to function as a workable and coherent moral or political principle. Therefore it works neither against Thomson's argument nor generally. ${ }^{\text {vi }}$ All in all, its absurdity as a principle of fairness explains why the principle yields the "surprising" and "paradoxical" (FitzPatrick's (2009: 640) own words) conclusion that it is permissible to divert the trolley onto another even if we are able but unwilling to divert it onto ourselves instead.

FitzPatrick's objection to Thomson does not work, then. But that, clearly, does not mean that Thomson's argument goes through. Specifically, FitzPatrick challenges also another aspect of Thomson's argument, where she argues that even those who would divert the trolley onto themselves in the three-way scenario, sacrificing their own lives, are not allowed to divert the trolley onto the one workman in the traditional Bystander at the Switch. Thomson claims that this sort of altruism is not "morally attractive" (2008: 366), and that anyway the bystander may not suppose that the workman is similarly altruistic.

As we have seen, almost $40 \%$ of respondents to the Moral Sense Test declare that they would commit self-sacrifice in the three-way scenario; that's why this part of Thomson's 
argument is important. If Thomson's argument would apply only to those who would not be willing to commit self-sacrifice, and if the numbers are to be taken seriously, then that would be a problem for her general conclusion that intervening in Bystander at the Switch is not permissible: indeed, that conclusion could not be generalized to a large part of the population. ${ }^{\text {vii }}$ That is why this second part of Thomson's argument in which she argues that even those supposed altruists may not intervene in Bystander at the Switch also matters.

FitzPatrick challenges this part of Thomson's argument by arguing that her appeal to the notion of consent "beg[s] the interesting questions... Those who believe that it is generally permissible to turn the trolley obviously think that this is a special case where consent isn't necessary. So Thomson's quick appeal to consent won't gain any traction with those who don't already share her view." (2009: 642).

Thomson writes that "the altruistic bystander is not entitled to assume that the one workman is equally altruistic, and would therefore consent to the bystander's choosing option (ii). Altruism is by hypothesis not morally required of us. Suppose, then, that the bystander knows that the one workman would not consent, and indeed is not morally required to consent, to his choosing option (ii)"viii (2008: 367).

Here FitzPatrick is right to point out that appealing to consent is problematic - because the whole point of the Trolley Problem is the intuition that killing the one workman may be permissible even against his consent - but FitzPatrick is wrong to think that consent is what the argument actually relies on. In criticizing the sort of altruism that may motivate the bystander to turn the trolley towards herself in the three-way scenario, Thomson argues that dying for the sake of five strangers is not morally valuable. Thomson says that "I would certainly not feel proud of my children if I learned that they value their own lives as little as that man values his" (2008: 367). It is this claim, which she cashes out in terms of altruism by devising her new three-way scenario, which is doing the philosophical work for Thomson: it is because dying for the sake of five strangers is not morally valuable that even the bystander that would sacrifice herself may not sacrifice someone else. Consent doesn't actually matter, as shown by the counterfactual that if dying for the sake of five strangers were morally valuable, then the bystander may turn the trolley against the one workman irrespective of the workman's consent.

In defusing FitzPatrick's challenge, then, we have uncovered the deep structure of Thomson's argument ${ }^{\mathrm{ix}}$ : it is not about consent, but rather about the moral value of dying for strangers. Let me just say that here it will not do to object that in the traditional Bystander at the Switch both the one and the five are strangers for the bystander: that is addressed by Thomson's new scenario, which supposedly shows that the bystander may not sacrifice the one if she is not willing to sacrifice herself. This is just a point about fairness and treating others as moral equals, which we have here defended from FitzPatrick's weaker principle. But it is when Thomson addresses those who would be willing to sacrifice themselves that her stronger normative claim emerges: dying for the sake of strangers is not morally valuable. Since it is not morally valuable, those who wish to do it will have to appeal to individual liberty to justify it; but liberty will only justify self-sacrifice, and not sacrificing others. That is then why even those who would, in the three-way scenario, sacrifice themselves, may not sacrifice the one workman in the traditional Bystander at the Switch. 
I have not only rebutted FitzPatrick's critique; I have also made explicit the crucial normative premise upon which Thomson's new argument is built: that it is not morally valuable to die for the sake of strangers. We see now that the real novelty in Thomson's new discussion of the Trolley Problem is not just the new three-way scenario involving self-sacrifice and its implications for the traditional scenario; Thomson has shown that we must defend the value of dying for the sake of strangers in order for the Trolley Problem to even arise. And because there is no moral value in dying for strangers, then there is no Trolley Problem. Here it is neither possible nor necessary to deal in depth with this sort of radical altruism: it is enough to have shown that the very existence of the Trolley Problem depends on taking a particular position on this radical altruism (and anyway, how many people do you know, for example, who have committed suicide so that their organs may be deployed to save the life of five strangers? ${ }^{x}$.

It may be objected that Thomson's dissolution of the Trolley Problem crucially depends on the characters involved being strangers. But, the objection goes, we can reformulate the Trolley Problem without this requirement, so that Thomson's argument would fail to dissolve this new version of the Trolley Problem because it could no longer rely on the point about dying for the sake of strangers. Let us then look at a variant on the Trolley Problem which includes the kind of features that, according to Thomson, may make self-sacrifice morally valuable: "They're my children," "They're my friends," "They stand for things that matter to me," "They're young, whereas I haven't much longer to live," "I've committed myself to doing what I can for them": these and their ilk would make sacrificing one's life to save five morally intelligible.

Consider, by contrast, the man who learns that five strangers will live if and only if they get the organs they need, and that his are the only ones that are available in time, and who therefore straightway volunteers. No reputable surgeon would perform the operation, and no hospital would allow it to be performed under its auspices. I would certainly not feel proud of my children if I learned that they value their own lives as little as that man values his (2008: 366-67).

Let us then take it that the five stuck on the main track are volunteers who have been trying to reach an isolated village in desperate need of water after an earthquake. And let us further suppose that the bystander knows the good work that the five have been doing through the years; the bystander thinks that the five are virtuous examples who must continue to provide an inspiration to society. The bystander concludes that, were she stuck on a third track towards which she could divert the runway trolley, she would sacrifice herself for the sake of the five. In order to maintain the symmetry of the original Trolley Problem, let us suppose that the one was also on her way to help the same isolated village, and that the bystander considers the one a virtuous example who must continue to provide an inspiration to society too. Is it now permissible for the bystander to sacrifice the one in order to save the five?

I see two problems here: firstly, once we have described the victims as exceptionally virtuous so as to provide an argument for self-sacrifice which the traditional Trolley Problem lacks, then the bystander may reasonably assume that the one would consent to being sacrificed; and on the other hand if the bystander were to think that the one would not consent, then she may no longer regard it as exceptionally virtuous - so that the symmetry with the traditional 
Trolley Problem would be lost one way or the other. The second problem is with Fat Man: apart from the plausibility of a very fat man taking part to a rescue operation, in this version of the Trolley Problem it is no longer clear that it would be clearly impermissible to shove the fat man off the bridge - indeed, for the considerations above, it may have to be supposed that the fat man would himself jump; and that if he didn't (jump or just give his consent to being pushed, as he might be too fat to climb the railing himself), the symmetry would no longer hold.

Here it may be objected that it is only by modelling the new variant on "They stand for things that matter to me" (2008: 366) that we run into problems; other variants will work better. Let us try: "They're my children" (ibid.) will not do because, if all six have to be my children, then I can't compare myself to the one, which has a different relation to the five than I do. And in general we would be contaminating the Trolley Problem with parental and fraternal commitments and responsibility which would make the problem non-basic in a way so as to radically change its role in normative ethics. These two kinds of considerations also apply, respectively, to "They're young, whereas I haven't much longer to live" (ibid.) and "I've committed myself to doing what I can for them" (ibid.): the former because the symmetry between my relation to the five and the one's relation to the five would be altered; the latter because of the special responsibilities with which we would alter the Trolley Problem. Finally, "They're my friends" (ibid.) will also not do because of reasonable assumptions about consent in both Bystander and Fat Man. What this suggests is that it is constitutive of the Trolley Problem that it features strangers; but, as Thomson argues, since it features strangers the Trolley Problem is not a problem because it is not permissible to kill the one in Bystander at the Switch.

Summing up, I have argued that criticising the Doctrine of Double Effect will, alone, not do. We must also offer an alternative explanation for the cases, such as the Trolley Problem, that the Doctrine can deal with. On these grounds I have defended a proposed dissolution of the Trolley Problem. It may be objected that the Doctrine may still be preferred to Thomson's dissolution on the grounds that the former but not the latter explains the Trolley Problem by accounting for lay intuitions that Bystander is permissible but Fat Man is not permissible; the latter challenges lay intuitions by arguing that Bystander is not actually permissible. So only the Doctrine really does justice to lay intuitions; my proposed alternative does not. And on this ground one may still hang on to double effect.

It is true that the conclusion of Thomson's new argument, which I have here defended, is that Bystander is not permissible; while empirical evidence suggests that the people (as Steinbeck would have said) think that Bystander is permissible. But the relationship between Thomson's new argument and intuitions which I have suggested here is different: my own experimental data suggest that the Bystander intuition is not basic in the way in which it has until now been suggested to be. When subjects answer the self-sacrifice scenario before they answer the Bystander scenario, then they no longer report the intuition that Bystander is permissible. So my proposal is not at a disadvantage against double effect on the grounds that the Doctrine does justice to wide-spread moral intuitions while my proposal does not: I have done justice to intuitions too by deploying Thomson's new argument to demonstrate that people don't really have the intuition that Bystander is permissible. ${ }^{\mathrm{xi}}$ 


\section{References}

Boyle, J.M. (1980), Toward Understanding the Principle of Double Effect. Ethics 90 (4): 527 538.

Foot, P. (1967), The problem of abortion and the doctrine of the double effect. Oxford Review 5: 5-15.

Di Nucci, E. (2008), Mind Out of Action. VDM Verlag.

Di Nucci, E. (2009), 'Simply, false', Analysis 69/1: 69-78.

Di Nucci, E. (2010), Rational constraints and the Simple View. Analysis 70 (3): 481-486.

Di Nucci, E. (2011), Automatic Actions: Challenging Causalism. Rationality Markets and Morals 2 (1): 179-200.

Di Nucci, E. (2013a), Self-Sacrifice and the Trolley Problem. Philosophical Psychology 26: 662-672.

Di Nucci, E. (2013b), Mindlessness. Newcastle upon Tyne: Cambridge Scholars Publishing.

Di Nucci, E. (2013c), 'Embryo Loss and Double Effect', Journal of Medical Ethics 39 (8): 537540.

Di Nucci, E. (2013d), 'Double Effect and Terror Bombing', in Hoeltje M. Spitzley T. \& Spohn W. (eds.), Was dürfen wir glauben? Was sollen wir tun? Sektionsbeiträge des achten internationalen Kongresses der Gesellschaft für Analytische Philosophie e.V. DuEPublico.

Di Nucci, E. (2014), Ethics Without Intention. London: Bloomsbury.

FitzPatrick, W.J. (2009), Thomson's turnabout on the trolley. Analysis 69 (4): 636-43.

Hauser, M. (2006), Moral Minds. New York: HarperCollins.

Huebner, B. \& Hauser, M. (2011), Moral judgments about altruistic self-sacrifice: When philosophical and folk intuitions clash. Philosophical Psychology 24 (1): 73-94.

Mangan, J.T. (1949), An Historical Analysis of the Principle of Double Effect. Theological Studies 10: 41-61.

Nagel, T. (1986), The View from Nowhere. Oxford University Press.

Petrinovich, L., and O'Neill, P., (1996), Influence of wording and framing effects on moral intuitions. Ethology and Sociobiology 17: 145-171.

Sinnott-Armstrong, W. (2008), Framing Moral Intuitions in W. Sinnott -Armstrong (Ed.) Moral Psychology, Volume 2: The Cognitive Science of Morality, (pp. 47-76). Cambridge, MA: MIT Press.

Swain, S., Alexander, J. and Weinberg, J. (2008), The Instability of Philosophical Intuitions: Running Hot and Cold on Truetemp. Philosophy and Phenomenological Research 76: 138155.

Thomson, J.J. (1976), Killing, letting die, and the trolley problem. The Monist 59: 204-17.

Thomson, J.J. (1985), The trolley problem. The Yale Law Journal 94: 1395-415.

Thomson, J.J. (2008), Turning the trolley. Philosophy and Public Affairs 36: 359-74.

Wiegmann, A., Okan, Y., Nagel, J. (2010), Order Effects in Moral judgment. Philosophical Psychology 25: 813-836.

Woodward, PA. (2001) (ed.), The doctrine of double effect. Notre Dame: University of Notre Dame Press.

\footnotetext{
' Here are some representative definitions of the Doctrine of Double Effect (for more on the Doctrine please see Di Nucci 2014):

- McIntyre in the Stanford Encyclopedia of Philosophy: "sometimes it is permissible to bring about as a merely foreseen side effect a harmful event that it would be impermissible to bring about intentionally" (http://plato.stanford.edu/entries/double-effect/);
} 
- Woodward in the Introduction to his standard anthology on double effect: "intentional production of evil... and foreseen but unintentional production of evil" (2001: 2);

- Aquinas, which is often credited with the first explicit version of double effect: "Nothing hinders one act from having two effects, only one of which is intended, while the other is beside the intention" (Summa II-II, 64, 7);

- Gury: "It is licit to posit a cause which is either good or indifferent from which there follows a twofold effect, one good, there other evil, if a proportionately grave reason is present, and if the end of the agent is honourable - that is, if he does not intend the evil effect" (Boyle's translation 1980: 528);

- Mangan: „A person may licitly perform an action that he foresees will produce a good and a bad effect provided that four conditions are verified at one and the same time: 1) that the action in itself from its very object be good or at least indifferent; 2) that the good effect and not the evil effect be intended; 3) that the good effect be not produced by means of the evil effect; 4) that there be a proportionately grave reason for permitting the evil effect" (1949: 43).

ii "I believe that the traditional principle of double effect, despite problems of application, provides a rough guide to the extension and character of deontological constraints, and that even after the volumes that have been written on the subject in recent years, this remains the right point of convergence for efforts to capture our intuitions" (Nagel 1986: 179).

${ }^{\text {iii }}$ Foot originally suggested that we explain the trolley case in terms of the difference between positive and negative duties (1967); her proposal was refuted by Thomson (1976 \& 1985), which in doing so introduced the Trolley Problem as we know it today. Please see my book Ethics Without Intention for details on the history of this debate (Di Nucci 2014).

${ }^{\text {iv }}$ Another consideration that is particularly relevant to this new case given that it involves self-sacrifice is the gap between the reports and what respondents would actually do were they really in such a situation.

${ }^{\vee}$ My argument about the data has been admittedly quite quick here; please see Di Nucci 2013a \& 2014 for more details.

${ }^{v i}$ I don't suppose that FitzPatrick ever meant it as a full-blown general principle, because, understood as not only necessary but also sufficient, it justifies, amongst others, psychopaths, mass-murderers, and in general most if not all of the major wrong-doers of this world.

vii This should not be overstated as Thomson's general conclusion that intervening in Bystander at the Switch is not permissible clearly clashes with general intuition, as $90 \%$ of respondents disagree with Thomson. But fortunately we haven't yet reached a point where these kinds of surveys alone are sufficient to refute normative claims.

viii Option (ii) is diverting the trolley towards the one workman.

${ }^{\text {ix }}$ Here I leave unanswered the question of which interpretation is actually closer to Thomson's original: it may be that my interpretation is preferable, and then what I offer here is a defence of Thomson. Or it may be that FitzPatrick's interpretation is closer to the original, and then what I offer here is my own argument, based on one by Thomson (and there is certainly something to say in favour of FitzPatrick's interpretation, as Thomson, after having considered the value of dying for strangers, writes "Perhaps you disagree. I therefore do not rely on that idea" (2008: 367), and goes on to talk about consent). I think this is just a question of copyright: nothing in the content of my argument hangs on whether it is more appropriately attributed to Thomson or myself.

${ }^{x}$ No one else will save those on waiting lists: "In the U.S. alone, 83,000 people wait on the official kidney-transplant list. But just 16,500 people received a kidney transplant in 2008 , while almost 5,000 died waiting for one" (WSJ 8.1.10).

${ }^{x i}$ Here I could not get into much detail about the Doctrine of Double Effect. Those who are interested in what I have to say about the ethical and action-theoretical issues surrounding the Doctrine may look at: Di Nucci 2008, Di Nucci 2009, Di Nucci 2010, Di Nucci 2011, Di Nucci 2013a, Di Nucci 2013b, Di Nucci 2013c, Di Nucci 2013d, and Di Nucci 2014. 